\title{
Dieta, Justícia Global i Sostenibilitat. Transformant pràctiques cap a la Cultura del Desenvolupament i la Pau
}

Jordi Domènech-Casal (jdomen44@xtec.cat) Institut Marta Estrada (Granollers), Departament de Didàctica de les Matemàtiques i les Ciències Experimentals, Universitat Autònoma de Barcelona

La nutrició i la dieta són conceptes que es solen treballar de manera pràctica en les aules de ciències mitjançant l'elaboració de dietes ajustades a necessitats calòriques i nutritives. L'educació pel Desenvolupament i la Pau és un enfoc educatiu que té per objectiu la construcció d'una ciutadania crítica i compromesa amb la transformació social en claus de justícia, sostenibilitat $i$ solidaritat $i$ connexió amb les problemàtiques globals. Hem desenvolupat una seqüència didàctica que, partint d'una proposta clàssica de treball d'elaboració d'una dieta sana, promou la connexió del node de l'alimentació amb diverses problemàtiques globals, com la justícia social $i$ el canvi climàtic. Fem una descripció de la seqüència $i$ els resultats d'aplicació $i$ considerem les possibilitats de transformació d'activitats d'ensenyament de les ciències amb enfocs similars com a aportació a la Cultura del Desenvolupament i la Pau.

Paraules clau: Cultura del Desenvolupament i la Pau, Nutrició, Petjada ecològica, Desigualtat, Micronutrients

Nutrition and diet are concepts usually taught un practical approaches as constructing proposals of diets set for a given caloric and nutritional needs. The Education for Peace and Development movement is an educational frame aiming the construction of a global citizenship with critical awareness and social engagement in reference to justice, sustainability, solidarity and connection with global challenges. On the basis of a classic didactic sequence for the construction of a wealthy diet, we have developed an activity that connects nutrition with several global problems, as social justice and climatic change. We describe the sequence and results of the application and consider the possibilities for the transformation of science didactic sequences with Education for Peace and Development frames.

Keywords: Development and peace culture, nutrition, ecological footprint, inequality, micronutrients.

\section{INTRODUCCIÓ}

El desenvolupament de la Competència Científica implica que l'alumnat estigui capacitat per a comprendre missatges i contextos on hi ha implicats models científics, decidir en conflictes participats per la Ciència i actuar com a ciutadà i membre d'una comunitat usant valors i coneixements científics (Domènech-Casal, 2018). Aquestes tres instàncies requereixen el desenvolupament d'habilitats de raonament científic, valoració de riscos i anàlisi crític i la capacitat d'usar marcs ètics i socials en la presa de decisions.

L'Educació per al Desenvolupament i la Pau pretén construir una ciutadania crítica, políticament activa i socialment compromesa amb èmfasi en la necessitat d'educar en i per al conflicte. És un enfocament educatiu que promou l'adquisició d'un consciència crítica sobre la realitat mundial i facilitar eines per a la participació i la transformació social en claus de justícia i solidaritat. Això suposa treballar la perspectiva positiva del conflicte i generar estratègies $i$ habilitats que ens ajudin a enfrontar-los 
de forma no violenta i ubicar-los en el mar de problemàtiques locals i globals (Mesa, 2000; Caireta, 2012).

En l'ensenyament de les Ciències, el concepte de nutrició i dieta equilibrada ocupa un espai important dins l'estudi de la funció de nutrició, tant al llarg de la primària com a secundària, de manera molt específica a $3 r$ d'ESO. Una aproximació generalitzada és la metàfora de la piràmide alimentària, en la que es representen aliments rics en diferents tipus de biomolècules (glúcids, lípids, proteïnes, ...) i les proporcions que s'associen a una dieta sana. L'enfoc cap a la dieta permet la problematització del tema de la nutrició i la ubicació en la presa de decisions, que sol adoptar la forma d'activitats en les que l'alumnat ha de confeccionar una dieta atenent a diverses restriccions (contingut calòric, aport proteic i vitamínic,...) i ajusts a situacions fisiològiques concretes (metabolisme basal, activitat física,..) amb l'objectiu que el treball a l'aula de ciències serveixi perquè l'alumnat es capaciti per prendre decisions en l'àmbit de la nutrició i la salut. Aquesta aproximació al tema s'assimila al marc metodològic dels Estudis de Cas, un tipus d'Aprenentatge Basat en Projectes que es basa en la proposta d'un escenari problemàtic (la configuració de la dieta per a una persona amb característiques concretes) en la resolució del qual l'alumnat va instrumentalitzant diversos coneixements (tipus de nutrients, concepte de caloria,...) de manera paulatina amb l'objectiu que en construeixi els significats en la seva instrumentalització (Domènech-Casal, 2017).

En la seva concreció en el món real, la dieta i l'elecció de quins aliments consumim (en el sentit de comprar i el de menjar) està també condicionada a problemàtiques globals vinculades al marc de l'Educació per al Desenvolupament i la Pau. En l'elecció dels aliments hi participen també aspectes relacionats amb els preus; el preus dels aliments depenen de mètodes de producció i distribució que no són neutres en relació al medi ambient i la justícia social: les verdures d'hivernacle o els manufacturats importats de lluny són més barats però suposen un cost ecològic mesurable en tones de $\mathrm{CO}_{2}$ (empremta ecològica), i determinats productes aconsegueixen preus o formats atractius mitjançant l'explotació laboral. Notícies d'actualitat mostren que és irreal la convicció que no existeixen aquestes implicacions o restriccions en la confecció de dietes, que es troba en un marc més complex que el de la piràmide alimentària: la pobresa és avui en països desenvolupats una font de malnutrició, evidenciant la relació entre dieta $\mathrm{i}$ desigualtats econòmiques
(InfoLibre, 2016), una relació que té també implicacions ecològiques.

\section{DESCRIPCIÓ DE LA SEQÜÈNCIA}

Hem desenvolupat $i$ aplicat una seqüència de construcció d'una dieta en la que els alumnes incorporen les dimensions ambiental i de justícia social que configuren la problemàtica. L'activitat, titulada "Dieta Sana, Justa i Sostenible" s'ha aplicat amb 54 alumnes de $3 r$ d'ESO de l'Institut Marta Estrada, de Granollers (Barcelona). Els materials de l'activitat han estat adaptats en base a les observacions durant l'aplicació i són disponibles a:

\section{Etapa 1. L'elecció d'una dieta implica components nutricionals i ecològiques.}

Es proposen als alumes 4 casos ficticis de persones (avatars), oferint per a cada cas una descripció d'edat, gustos culinaris, necessitats nutricionals i pressupost disponible, amb l'objectiu que proposin dietes d'un dia que responguin als requeriments de cada avatar cenyint-se als límits de preu i impacte ecològic. Com a suport, es proposa a l'alumnat un full de càlcul que en establir el nombre de racions de $100 \mathrm{grs}$. de diferents aliments permet obtenir de retorn un resultat del total de calories, micronutrients, preu i impacte ecològic de la dieta proposada (Figura 1).

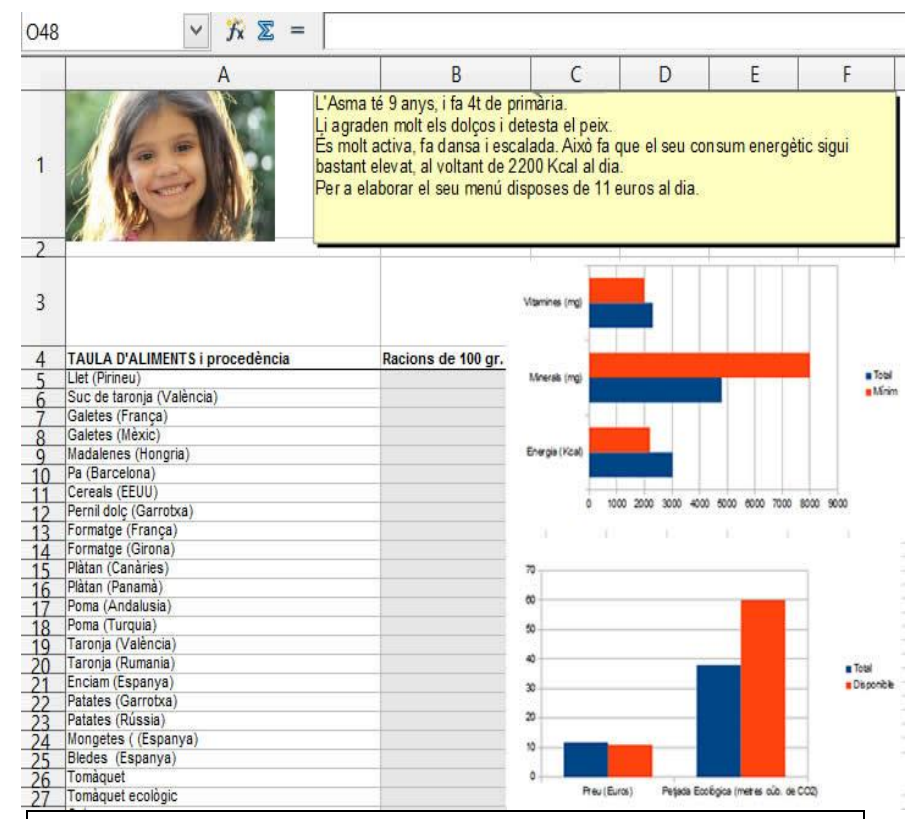

Figura 1. Imatge del full de càlcul, amb un dels avatars, que en introduir el nombre de racions de cada aliment mostra el resultat d'aquesta dieta en diversos aspectes (calòric, nutrients, empremta, preu). 
Els alumnes llegeixen en diverses fases informacions relatives als conceptes de dieta, nutrients i micronutrients i empremta ecològica i usen aquesta informació (quins aliments provoquen més impacte, quins tenen més contingut calòric, quines conseqüències per a la salut té la malnutrició...) per anar ajustant el nombre de racions i tipus d'aliments i aconseguir per a cada avatar una dieta que complexi els requisits. L'activitat està dissenyada perquè per a alguns dels avatars no sigui possible satisfer totes les condicions. En aplicar-ho i discutir-ne a classe, els alumnes opten per "sacrificar" la component ecològica, proposant per a aquest avatar aliments més barats però menys sostenibles o per acceptar la malnutrició (la manca de micronutrients). Aquesta etapa de l'activitat evidencia que les decisions sobre consum tenen implicacions nutricionals, però també ecològiques, i van més enllà de "molt menjar "o "poc menjar".

\section{Etapa 2: La justícia social està implicada en els aspectes de dieta i sostenibilitat.}

Es proposa a l'alumnat que torni a fer l'activitat ara amb la possibilitat de sumar el pressupost de tots els avatars i repartir-lo segons necessitats (Figura 2). En aquestes condicions sí que és possible satisfer les condicions per a tots els avatars (dieta sana y sostenible), si bé algun dels avatars no té una dieta ajustada als seus gustos culinaris. En aquesta etapa els alumnes aprenen que en la problemàtica de la nutrició hi participen també components de justícia social, evidenciant que una alimentació sana i sostenible no necessita només d'innovacions tecnològiques, sinó també de mecanismes de distribució de la riquesa.

\section{Etapa 3: La nutrició és una problemàtica global amb impactes globals.}

Es proposa ara als alumnes que es distribueixin per equips i a cada equip se li demana alimentar els 4 avatars amb un pressupost global diferent $(10,15$, 20, 30 euros...), emulant països amb diferents nivells de riquesa. En completar l'intent, els resultats dels diferents equips (països) es comparteixen a la pissarra, mostrant quins països aconsegueixen aport calòric suficient, nivell adequat de micronutrients i no superar l'empremta ecològica màxima. Els resultats il-lustren com alguns països no poden nodrir els 4 avatars, d'altres sí, però amb dèficits de micronutrients, mentre d'altres poden aconseguir fins i tot l'empremta ecològica i els gustos culinaris dels avatars, sempre en relació al seu pressupost global.

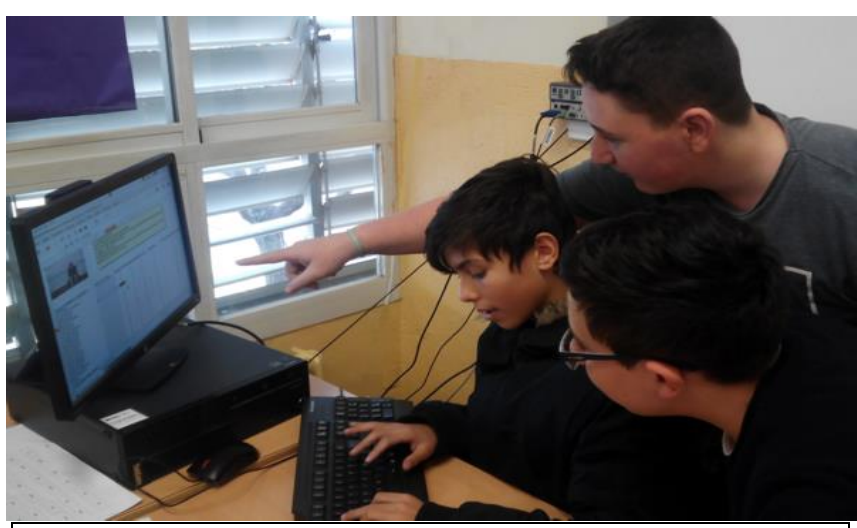

Figura 2. Alumnes en el procés de decidir canvis en la dieta d'un dels avatars.

\section{Etapa 4. Prendre decisions en contextos problemàtics globals.}

En aquesta etapa es proposa als alumnes un dilema (fictici), amb l'encàrrec d'escriure un assaig individual defensant la seva posició. El dilema és el següent: La normativa europea LG-234 obligarà tots els estats a aplicar un impost del 10\% (s'apujarà el preu) dels productes que tinguin una empremta ecològica forta, per lluitar contra el canvi climàtic. Pensa quines conseqüències pot tenir per a les persones que has estudiat $i$ argumenta si estàs a favor o en contra de la normativa i en cas que no, quina solució alternativa proposaries.

Tal com proposem en altres activitats (Domènech-Casal, Marchán i Vergara, 2015), abans d'escriure l'assaig els alumnes fan un debat on proposen els seus arguments en relació al dilema. Al llarg del debat emergeix un lèxic clau que procurem que es mantingui visible i els alumnes fan al-lusions als avatars pel seu nom "L'Asma no tindrà accés a vitamines" i vinculen aspectes personals $i$ globals "Si no es redueix l'impacte ecològic, a la llarga és pitjor per a tots" integrant aspectes ètics, ecològics i nutricionals.

$$
\begin{aligned}
& \text { \#DretsHumans \#desigualtat } \\
& \text { \#subvenció \#explatació } \\
& \begin{array}{l}
\text { \#malnutrició } \quad \text { \#riquesa } \\
\text { \#importació }
\end{array} \\
& \text { \#decreixement \#impost }
\end{aligned}
$$

Figura 3. Núvol de termes de lèxic emergits en el debat previ a l'escriptura de l'assaig. 
En els assajos de l'alumnat apareixen solucions diverses que impliquen distribució de la riquesa, desenvolupament sostenible de l'agricultura, programes específics de subvenció de tipus d'aliments, visions sobre el consumisme, malbaratament d'aliments...

Considerem que l'activitat permet als alumnes connectar la dieta des d'un espai o percepció local i nutricional a problemàtiques globals, i que aquesta via de transformació d'activitats pot ser d'utilitat per al desplegament de l'Educació pel Desenvolupament i la Pau. L'activitat permet ser desenvolupada en diverses línies (restriccions específiques per a persones malaltes, desforestació, crisi hídrica, drets laborals i explotació...) i transferir-la a altres aspectes del consum que no siguin els nutricionals. La seqüència tal com es proposa desenvolupa dues de les instàncies proposades per a la Competència Científica per a la Ciutadania (comprendre, decidir), però no la instància "Actuar": els alumnes no duen a terme accions ni iniciatives que desenvolupin les seves decisions. Pensem que això es pot fer com a cloenda de l'activitat tant a nivell personal o local (proposant a casa opcions de consum diferents) com a nivell social (en el marc de projectes d'Aprenentatge Servei o Ciència Ciutadana). L'activitat forma part de la col-lecció d'activitats didàctiques Sustainable-Me [2] que aborda la sostenibilitat des de diferents eixos, incloent l'ecologia, la gestió de residus i el decreixement.

\section{AGRAIIMENTS}

Reflexions incloses en aquest article s'inclouen en el treball de desplegament del pla STEAMCat del Departament d'Ensenyament de la Generalitat de Catalunya i la reflexió metodològica del grup d'investigació consolidat LICEC (referència 2014SGR1492) per AGAUR i finançat per el Ministerio de Economía y Competitividad (referència EDU2015-66643-C2-1-P).

\section{REFERÈNCIES}

CAIRETA, M. (2012). L'educació per la cultura de la pau en el context europeu. Escola de Cultura de la

Pau.

[http://escolapau.uab.es/img/programas/educaci on/marceuropeu_021012.pdf ]

DOMÈNECH-CASAL, J. (2017). Aprendizaje Basado en Proyectos y Competencia Científica. Experiencias y propuestas para el método de Estudios de Caso. $X$ congreso Internacional sobre Investigación en Didáctica de las Ciencias (Sevilla). Enseñanza de las Ciencias, Septiembre 2017 (número extraordinario) 51775183.

DOMÈNECH-CASAL, J. (2018). Comprender, Decidir y Actuar: una propuesta-marco de Competencia Científica para la Ciudadanía. Revista Eureka sobre Enseñanza y Divulgación de las Ciencias 15 (1), 1105.

DOMĖNECH-CASAL, J., MARCHÁN-CARVAJAL, I., VERGARA, Q. (2015). Experiències d'aula amb el treball amb Contro-vèrsies SòcioCientífiques. Educació per al Desenvolupament i la Salut, Pseudociències i eines per a l'avaluació d'activitats. Revista Ciències, 30, 32-38.

INFOLIBRE (2016). La tasa de pobreza infantil severa en España crece en medio millón más de niños afectados desde el 2008. Info Libre, 11/0//16.

[https://www.infolibre.es/noticias/politica/2016/07 111/la_tasa_pobreza_infantilsevera_espana_cr ece_medio_millon_ninos_afectados_mas_desd e_2008_52402_1012.html]

MESA, M. (2000). La educación para el desarrollo: entre la caridad y la ciudadanía global. Papeles de Cuestiones Internacionales, 70, 11-26.

[1] Materials didàctics del projecte: https://app.box.com/s/id6dhcq9ufuib6rggva2ytzk $1 \mathrm{kq} 907 \mathrm{q} 4$

[2] Col-lecció d'activitats Sustainable-Me: https://sites.google.com/site/sustain2me/ 